\title{
A HYBRID METHOD FOR EVALUATING OF LIGHTNING PERFORMANCE OF OVERHEAD LINES BASED ON MONTE CARLO PROCEDURE
}

\author{
Reza Shariatinasab* — Pooya Tadayon * Akihiro Ametani ${ }^{* *}$
}

\begin{abstract}
This paper proposes a hybrid method for calculating lightning performance of overhead lines caused by direct strokes by combining Lattice diagram together with the Monte Carlo method. In order to go through this, firstly, the proper analytical relations for overvoltages calculation are established based on Lattice diagram. Then, the Monte Carlo procedure is applied to the obtained analytical relations. The aim of the presented method that will be called 'ML method' is simply estimation of the lightning performance of the overhead lines and performing the risk analysis of power apparatus with retaining the acceptable accuracy. To confirm the accuracy, the calculated results of the presented ML method are compared with those calculated by the EMTP/ATP simulation.
\end{abstract}

K e y w ords: lightning performance, overhead lines, Monte Carlo method, risk analysis

\section{INTRODUCTION}

The lightning overvoltage is one of the main causes of insulation failure of power networks. The insulation level of overhead lines, especially on distribution networks, is determined based on the basis of lightning overvoltages. In other word, the proper selection of basic lightning impulse insulation level (BIL) of power apparatus leads to reduction of lightning flashover rate (LFOR) of the overhead lines.

The lightning flashover may be caused by either direct strokes to overhead line or nearby strokes producing induced overvoltages. Most of transmission lines have sufficient strength to be immune to the induced overvoltages. Therefore, the induced voltages are more of a concern on distribution lines [1]. The LFOR of overhead lines caused by direct strokes are the sum of the outages originated from strokes hitting phase conductors, $i e$ shielding failure flashover rate (SFFOR) and those hit shield wire or the tower, ie back flashover rate (BFR) [2].

The conventional existed methods for estimating lightning performance of overhead lines are based on analytical methods or Monte Carlo simulation. In analytical methods the obtained equations for overvoltage calculation must be solved by means of numerical methods in which their accuracy is somehow questioned because of the integrations needed to solve the corresponding equations [3]. Besides, the conventional Monte Carlo based methods include a lot of simulations that must be performed by a simulation software that is time consuming $[4,5]$. However, owing to the random nature of lightning, it is understood that any precise assessment of lightning related overvoltages should be carried out based on statistical approaches as the Monte Carlo method [5-8].
This paper presents a hybrid method to estimate the lightning overvoltages that is a combination of the travelling wave theory ie analytical method and Monte Carlo procedure. The applied Monte Carlo procedure consists of generation of random numbers to obtain those parameters of the lightning stroke and the overhead line having random nature; application of an incidence model to determine the point of impact of every lightning stroke; calculation of the overvoltage generated by each stroke, depending on the point of impact; and calculation of the LFOR [9].

The proposed procedure, ie ML Method, benefits from the simplicity of lattice diagram together with the accuracy of the Monte Carlo simulation. In addition, the processing time of the proposed method is much less than to the conventional approaches for which usually a case study should be modelled and many simulations must be run to obtain the results. However, all the stages of the proposed method have been coded in MATLAB environment and no software simulation is required.

\section{THE CONCEPT OF EGM MODEL}

\subsection{Impact area of lightning to ground}

Usually, it is assumed that termination point of vertical strokes of lightning surges is distributed uniformly in an impact area, Fig. $1[5,10]$. The length of this area is equal to the line span and its width, d, is calculated corresponding to the maximum peak current magnitude of the lightning stroke.

\subsection{Termination point of impact}

The termination point of impact (strokes to the tower and phase conductor) can be determined by means of

\footnotetext{
${ }^{*}$ Electrical and Comp. Eng. Depart., University of Birjand, POB 97175/376, Birjand, Iran, shariatinasab@birjand.ac.ir; ${ }^{* *}$ Faculty of Engineering, Doshisha University, Kyo-Tanabe, Kyoto, Japan
} 


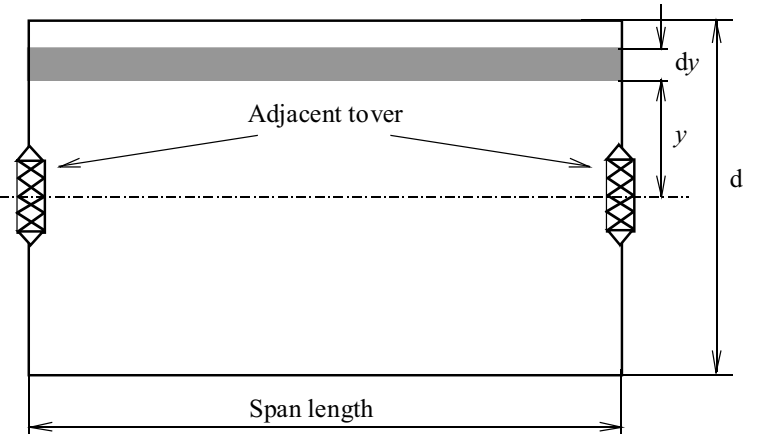

Fig. 1. The area of lightning impact [5]

an EGM model of overhead lines, in which the striking distances are suggested by Rizk [11] and used by IEEE Std. $1243[2]$ as

$$
\begin{gathered}
r_{c}=10 I^{0.65}, \\
R_{g}= \begin{cases}{\left[3.6+1.7 \ln \left(43-y_{c}\right)\right] I^{0.65},} & y_{c}<40 \mathrm{~m}, \\
5.5 I^{0.65}, & y_{c} \geq 40 \mathrm{~m}\end{cases}
\end{gathered}
$$

where $r_{c}$ and $r_{g}$ are striking distance to the shield wire and ground, respectively; $I$ is the peak current magnitude and $y_{c}$ is the average conductor height. Assuming vertical strokes, depending on the point of impact of the lightning stepped leader, shielding failure (SF) or backflashover (BF) might be occurred.

\section{DEVELOPMENTS}

In this work, the authors propose an approach based on travelling wave theory and lattice diagram concept so that the proper equations are established to determine the crest voltage at the tower top and/or across the insulator string.

Due to travelling wave theory, impinging waves on any point of discontinuity produce both reflected and transmitted waves. So the first task is to calculate the reflection and transmission coefficients as shown in Fig. 2. Thereafter, the lattice diagram is constructed with time increasing downward. Starting with the time $t=0$, it is defined as the time that the lightning surge hit the overhead line; the voltage at the struck point can be calculated by adding reflected voltage waves travel back to the struck point from any point of discontinuity to the voltage wave originated by the lightning surge.

Once the lightning stroke hit the tower top, a voltage ' $e(t)$ ' is produced at the top of the tower that creates a travelling wave that travels down to the tower and out on the overhead ground wire. Due to Fig.2(a), the voltage ' $e(t)$ ' is given by

$$
e(t)=Z_{\text {in }} \times I(t)=\left(\left(Z_{g} / 2\right) \| Z_{T}\right) \times I(t)
$$

where $Z_{g}$ is the shield wire surge impedance, $Z_{T}$ is the tower's surge impedance and $I(t)$ is the instantaneous lightning current.

Considering reflections from adjacent towers, as shown in Fig. 2(b), the obtained voltage on top of the struck tower depends on the tower travel time, $T_{T}$, span travel time, $T_{g}$, footing resistance of struck tower, $R_{i}$, and footing resistance of adjacent towers, $R_{\circ}$. Then, the tower top voltage $V_{T}$ can be introduced in the form of

$$
\begin{aligned}
& V_{T}=e(t)+V_{1 N T}+V_{2 N T}+V_{3 N T}+\cdots+V_{G R}+ \\
& V_{G R-N T(1)}+V_{G R-N T(2)}+\cdots+V_{G R 1 N T}+V_{G R 2 N T}+\ldots
\end{aligned}
$$

where $V_{i N T}(i=1,2,3, \ldots)$ is reflected voltage from $i$ th adjacent tower, $V_{G R}$ is reflected voltage from footing of the struck tower, $V_{G R-N T(i)}(i=1,2,3, \ldots)$ is the reflected voltage from the footing of the $i$-th adjacent tower; $V_{G R 1 N T}$ is caused by that part of $V_{G R}$ travelling to the adjacent tower top and reflecting back to the struck tower; $V_{G R 2 N T}$ is caused by that part of $V_{N T}$ that is transmitted onto the struck tower and travels back to the tower top after reflection from the tower footing. However, each voltage component must be added with respect to its time at the struck tower. The voltage of interests can be calculated by the following equations

$$
\begin{aligned}
V_{1 N T} & =2 \beta \alpha e\left(t-2 T_{g}\right)+\beta^{3} \alpha e\left(t-4 T_{g}\right) \\
& +\beta^{5} \alpha e\left(t-6 T_{g}\right)+\ldots
\end{aligned}
$$

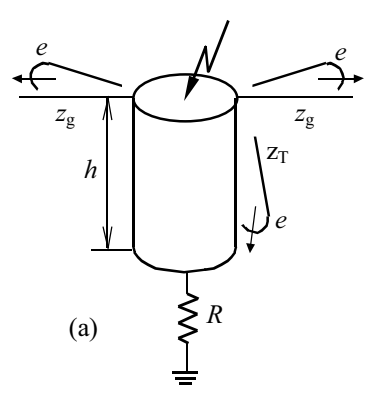

(b)

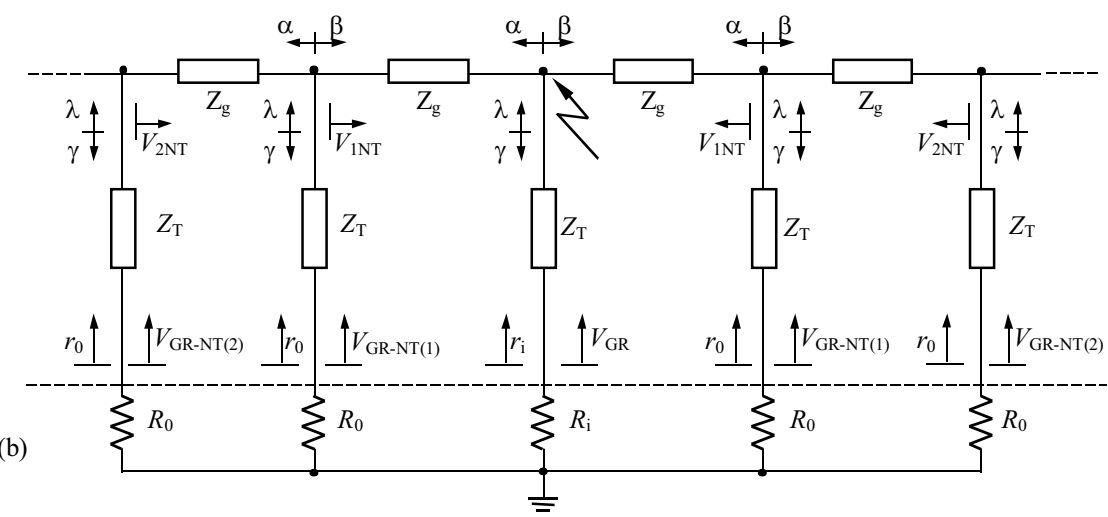

Fig. 2. Application of lattice diagram for calculation of crest voltage, (a) — Stroke to tower [3], (b) - Effect of adjacent towers on crest voltage 


$$
\begin{gathered}
V_{2 N T}=2 \alpha^{3} \beta e\left(t-4 T_{g}\right)+\alpha^{5} \beta^{3} e\left(t-8 T_{g}\right) \\
\quad+\alpha^{7} \beta^{5} e\left(t-12 T_{g}\right)+\ldots \\
V_{3 N T}=2 \alpha^{5} \beta e\left(t-6 T_{g}\right)+\alpha^{7} \beta^{5} e\left(t-12 T_{g}\right) \\
\quad+\alpha^{9} \beta^{7} e\left(t-18 T_{g}\right)+\ldots \\
V_{G R 1 N T}=2 \alpha^{2} r_{\circ} \lambda e\left(t-2 T_{g}-2 T_{T}\right) \\
\quad+\alpha^{3} r_{\circ} \lambda \beta e\left(t-4 T_{g}-2 T_{T}\right)+\ldots \\
V_{G R 2 N T}=\alpha^{4} r_{\circ} \lambda e\left(t-4 T_{g}-2 T_{T}\right) \\
\quad+\alpha^{7} r_{\circ} \lambda \beta e\left(t-8 T_{g}-2 T_{T}\right)+\ldots \\
V_{G R}=2 r_{i} \lambda e\left(t-2 T_{T}\right)+r_{i}^{2} \lambda \gamma e\left(t-4 T_{T}\right) \\
\quad+r_{i}^{3} \lambda \gamma^{2} e\left(t-6 T_{T}\right)+\ldots \\
V_{G R-} N T(1)=2 r_{i} \lambda \beta \alpha e\left(2-2 T_{T}-2 T_{g}\right) \\
\quad+r_{i}^{2} \lambda^{2} \beta^{2} \alpha^{2} e\left(t-4 T_{T}-4 T_{g}\right)+\ldots \\
V_{G R-} N T(2)=2 r_{i} \gamma \lambda \beta \alpha^{2} e\left(t-4 T_{T}-2 T_{g}\right) \\
\quad+r_{i}^{2} \gamma^{2} \lambda \beta \alpha^{4} e\left(t-6 T_{T}-2 T_{g}\right)+\ldots \\
V_{G R-} N T(3)=2 r_{i} \gamma \lambda \beta \alpha^{3} e\left(t-6 T_{T}-2 T_{g}\right) \\
+r_{i}^{3} \gamma^{3} \lambda^{2} \beta \alpha^{6} e\left(t-6 T_{T}-2 T_{g}\right)+\ldots
\end{gathered}
$$

where the reflection and transmission coefficients are as follows

$$
\begin{aligned}
\lambda & =\frac{Z_{g}}{Z_{g} / 2+Z_{T}}, & \gamma & =\frac{Z_{g} / 2-Z_{T}}{Z_{g} / 2+Z_{T}}, \\
r_{i} & =\frac{R_{i}-Z_{T}}{R_{i}+Z_{T}}, & r_{o} & =\frac{R_{o}-Z_{T}}{R_{o}+Z_{T}}, \\
\alpha & =\frac{2\left(Z_{g} \| Z_{T}\right)}{\left(Z_{g} \| Z_{T}\right)+Z_{g}}, & \beta & =\frac{\left(Z_{g} \| Z_{T}\right)-Z_{g}}{\left(Z_{g} \| Z_{T}\right)+Z_{g}} .
\end{aligned}
$$

It should be mentioned that equation (5) does not include either transmission line losses or frequency dependence of line parameters. The effect of reflected voltages from adjacent towers have been considered till the span travel time between the neighbour towers and the struck tower is less than the rise time of the lightning current waveform.

As the footing resistance of the struck tower, $R_{i}$, used in (7), is dependent on the magnitude of the lightning current; its nonlinear behaviour is approximated by [12]

$$
R_{i}=\frac{R_{t}}{\sqrt{1+I\left(\frac{2 \pi R_{t}^{2}}{\rho E_{g}}\right)}}
$$

where $I$ is the current passing through tower base resistance, $R_{t}$ is the footing resistance at low current and low frequency, $E_{g}$ (here $\left.300 \mathrm{kV} / \mathrm{m},[13]\right)$ is the soil ionization gradient, and $\rho(\Omega \mathrm{m})$ is the soil resistivity.

Having the tower top voltage $\left(V_{T}\right)$, given by (4), the crest voltage at any point across the tower as in cross arm $\left(V_{A}\right)$ can be calculated. Then, the crest voltage on the phase conductor $\left(V_{C}\right)$ is defined as (10) and the crest voltage across the insulation $\left(V_{\text {Ins. }}\right)$ can be calculated by (11). The meaning of various parameters is illustrated in Fig. 3 .

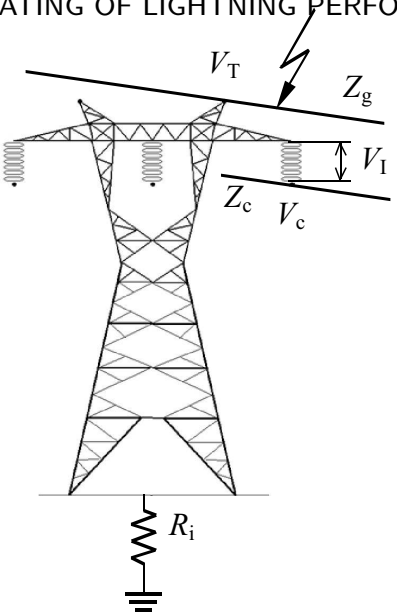

Fig. 3. Surge voltage at the tower and across the insulation

$$
\begin{gathered}
V_{C}=C V_{A}-V_{L N} \sin (\omega t) \\
V_{\text {Ins. }}=V_{A}-V_{C}=(1-C) V_{A}+V_{L N} \sin (\omega t)
\end{gathered}
$$

where $C$ is the coupling factor and $V_{L N} \sin (\omega t)$ is the line-neutral power frequency voltage at the instant of the stroke termination.

In the case of shielding failure occurrence, the maximum voltage produced across the insulator string is

$$
V=Z_{c} \frac{I_{p}}{2}
$$

where $I_{p}$ is the peak current magnitude of lightning surge and $Z_{c}$ is the conductor surge impedance under corona [12].

\section{MONTE CARLO PROCEDURE}

The Monte Carlo procedure that is used to calculate the lightning overvoltages consists of the following steps:

- Generating random numbers of the variables with the random nature including parameters of the lightning stroke, phase conductor voltages, and the footing resistance.

The main lightning parameters for overvoltage calculation include current peak magnitude, $I_{p}$, rise time, $T_{r}$, and time to half value $T_{t}$, in which their probability distribution function is assumed to be log-normal distribution [14]

$$
p(u)=\frac{1}{\sqrt{2 \pi} \sigma_{\ln u} u} \exp \left\{-\frac{1}{2}\left(\frac{\ln u-\ln \bar{u}}{\sigma_{\ln u}}\right)^{2}\right\}
$$

where $\sigma_{\ln u}$ is the standard deviation of $\ln u$, and $\bar{u}$ is the median value of $u$. The parameters of the negativepolarity stroke considered in the paper are shown in Table 1. $\rho_{c}$ is the correlation coefficient between the peak current magnitude and front time.

It is assumed that each tower footing resistance has also a log-normal distribution with the mean value of the resistance at low current and low frequency, $R_{t}$, and a standard deviation of $1.05 \Omega$ [15]. Having $R_{t}$, the equivalent nonlinear resistance of tower footing $R_{i}$, given by (9), was included in the overvoltage calculation.

The effect of the phase angle of the impressed voltage has been taken into account by considering it as a uniformly distributed variable between $0^{\circ}$ and $360^{\circ}$. 


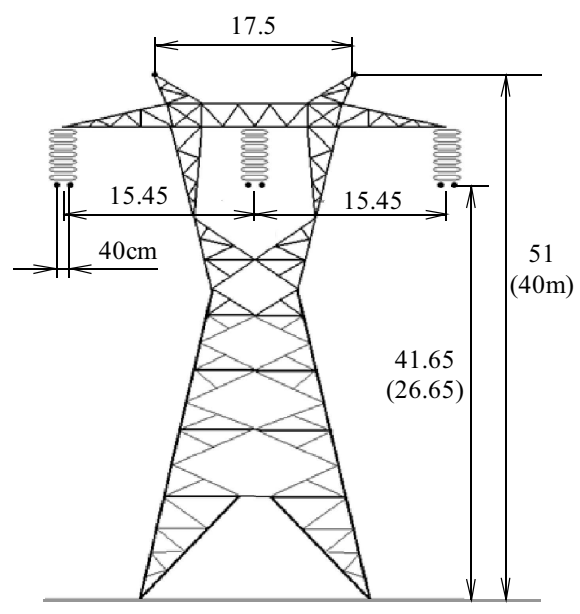

Fig. 4. Typical $400 \mathrm{kV}$ line configuration

Table 1. Log-normal statistical parameters of negative lightning strokes [14]

\begin{tabular}{cccc}
\hline Parameter & $I_{p}$ & $T_{r}$ & $T_{t}$ \\
\hline $\bar{u}$ & 34 & 2 & 77.5 \\
$\sigma_{\ln u}$ & 0.74 & 0.4943 & 0.577 \\
$\rho_{c}\left(I_{p}, T_{t}\right)$ & & 0.47 & \\
\hline
\end{tabular}

Table 2. Lightning overvoltage distribution $\left(R_{i}=50 \Omega, \rho=\right.$ $1000 \Omega-\mathrm{m})$

\begin{tabular}{c|cccc}
\hline \multirow{2}{*}{ Case } & \multicolumn{3}{|c}{ ATP simulation } & \multicolumn{2}{c}{ ML method } \\
\cline { 2 - 5 } & $\mathrm{SF}$ & $\mathrm{BF}$ & $\mathrm{SF}$ & $\mathrm{BF}$ \\
\hline Mean value $(\mathrm{kV})$ & 7090.6 & 997.1 & 7155.6 & 1014.5 \\
Standard deviation $(\mathrm{kV})$ & 6740.3 & 1248 & 6766.4 & 1273.3 \\
Mean Value/(Std. Dev.) & 1.052 & 0.798 & 1.057 & 0.796 \\
Max. value $(\mathrm{kV})$ & 14654 & 14782 \\
LFOR $\left(N_{g}=1 \mathrm{fl} / \mathrm{km}^{2} /\right.$ year $)$ & 3.98 & 3.67 \\
Insulation risk $(\%)$ & 31.4 & 31 \\
Computation Time $(\mathrm{s})$ & 20000 & 50 \\
\hline
\end{tabular}

Table 3. Lightning overvoltage distribution $\left(R_{i}=10 \Omega, \rho=\right.$ $100 \Omega-\mathrm{m})$

\begin{tabular}{c|cccc}
\hline \multirow{2}{*}{ Case } & \multicolumn{2}{|c}{ ATP simulation } & \multicolumn{2}{c}{ ML method } \\
\cline { 2 - 5 } & $\mathrm{SF}$ & $\mathrm{BF}$ & $\mathrm{SF}$ & $\mathrm{BF}$ \\
\hline Mean value $(\mathrm{kV})$ & 7088.3 & 749.4 & 7015.6 & 754.9 \\
Standard deviation $(\mathrm{kV})$ & 6724.8 & 1123 & 6648.6 & 1127.1 \\
Mean Value/(Std. Dev.) & 1.054 & 0.667 & 1.055 & 0.669 \\
Max. value $(\mathrm{kV})$ & 11815 & 11780 \\
LFOR $\left(N_{g}=1 \mathrm{fl} / \mathrm{km}^{2} /\right.$ year $)$ & 1.80 & 1.75 \\
Insulation risk $(\%)$ & 21.2 & 21.27 \\
Computation Time $(\mathrm{s})$ & 20000 & \multicolumn{2}{c}{50} \\
\hline
\end{tabular}

- Application of an EGM incidence model to determine the termination point of impact of each lightning stroke $I_{p}$, hitting overhead line. Once the point of impact has been determined, the overvoltage calculation is performed. In the case of BF occurrence, equations (4) and in the case of SF occurrence equation (12) were used to estimate the resultant overvoltage.

- Comparing overvoltages to the insulator strength, the flashover occurrence can be concluded. Then, depending on the point of impact, BFR and SFFOR were obtained.

\section{SIMULATION AND RESULTS}

The proposed method has been applied to a $400 \mathrm{kV}$ overhead line with $\mathrm{BIL}=1050 \mathrm{kV}$. The typical configuration of line is presented in Fig. 4. The span length is $400 \mathrm{~m}$.

The Heidler model is used to represent the lightning current waveform [16]

$$
I(t)=\frac{I_{p}}{\eta} \frac{k^{n}}{1+k^{n}} e^{-t / \tau_{2}}
$$

where $I_{p}$ is the peak current magnitude, $\eta$ correction factor of the peak current, $n$ the steepness factor, with $k=t / \tau_{1} ; \tau_{1}$ and $\tau_{2}$ are the time constants determining the current rise and decay times, respectively.

Two values of footing resistance 1) $R_{t}=50 \Omega$ with $\rho=1000 \Omega \mathrm{m}$; and 2) $R_{t}=10 \Omega$ with $\rho=100 \Omega \mathrm{m}$ were investigated. The calculated voltage waveform across the insulator string caused by BF, for a $40 \mathrm{kA}, 3.1 / 70 \mu \mathrm{s}$ lightning surge, is presented in Fig. 5. The multiple reflections from the footing resistance of the struck tower are included in Fig. 5. The first and second reflection is clear, while other reflections have a very small magnitude and overlap each other.

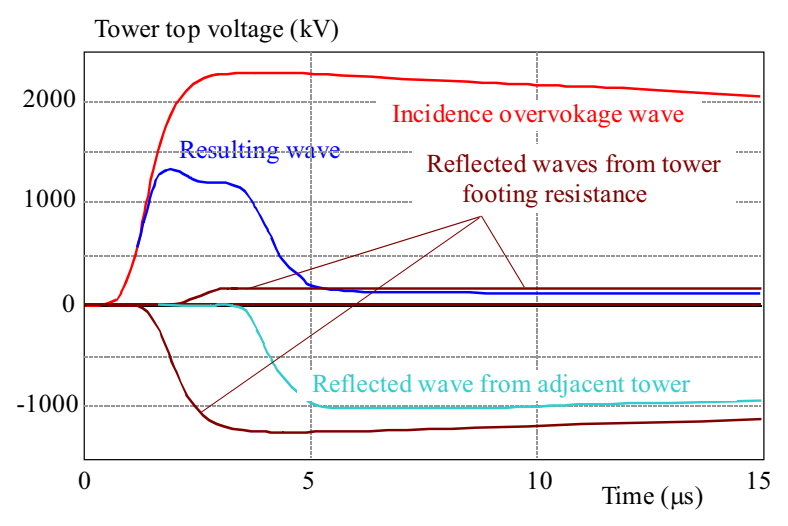

Fig. 5. Overvoltage wave at tower top caused by BF $\left(R_{i}=50 \Omega\right.$, $\rho=1000 \Omega \mathrm{m})$

As shown in Fig. 5, the waveshape of the voltage across the insulator string significantly differs from the standard impulse waveshape. Therefore, in order to estimate the lightning flashover rate, the leader progression model of insulator string was used [12]:

$$
\frac{\mathrm{d} l}{\mathrm{~d} t}=k \times V_{\text {Ins. }}(t)\left[\frac{V_{\text {Ins. }}(t)}{g-l}-E_{o}\right]
$$



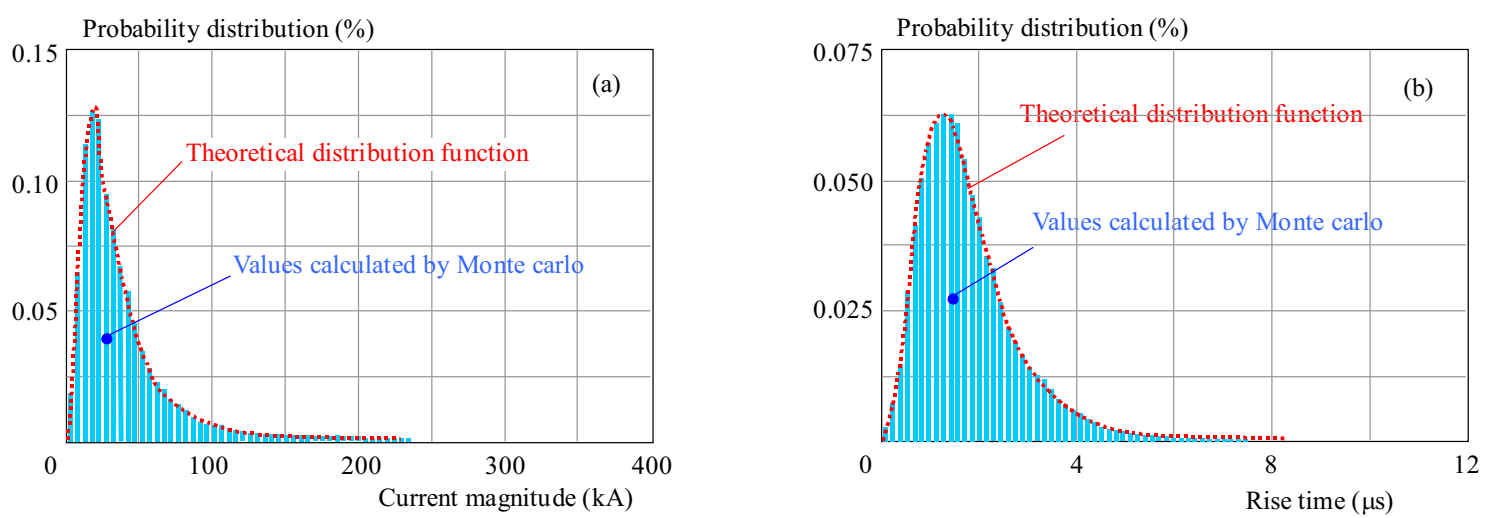

Fig. 6. Convergence of randomly generated values, (a) - distribution of peak current magnitude, (b) - distribution of rise
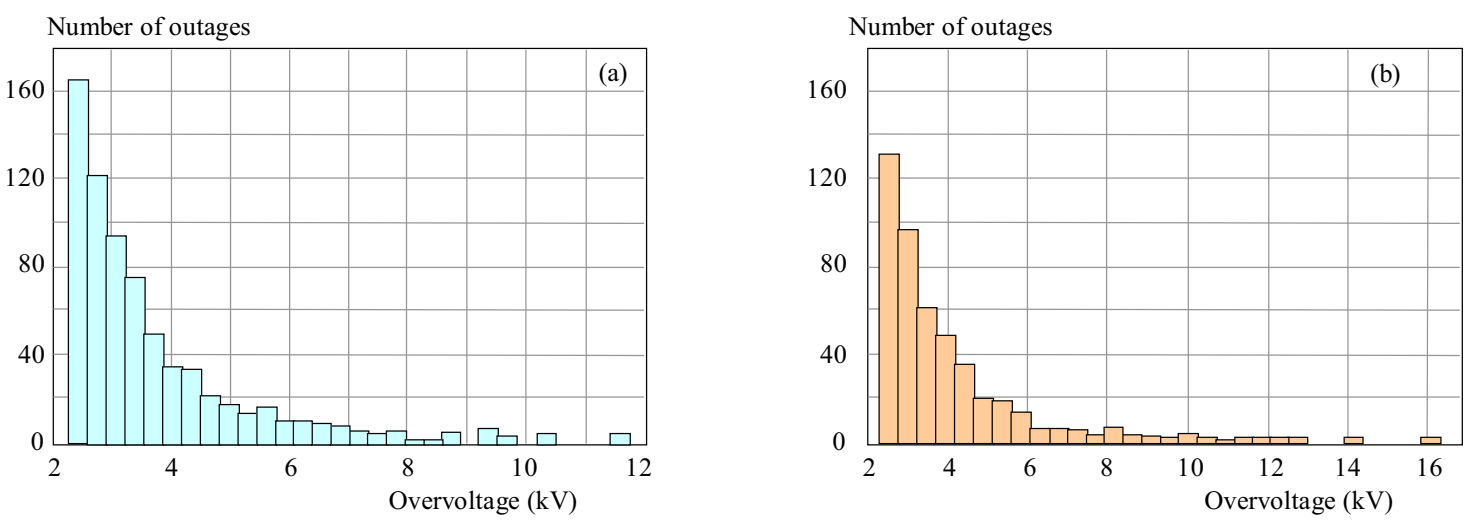

Fig. 7. Distribution of overvoltages causing $\operatorname{BFR}\left(R_{i}=50 \Omega, \rho=1000 \Omega-\mathrm{m}\right)$, (a) - ATP simulation, (b) - ML method
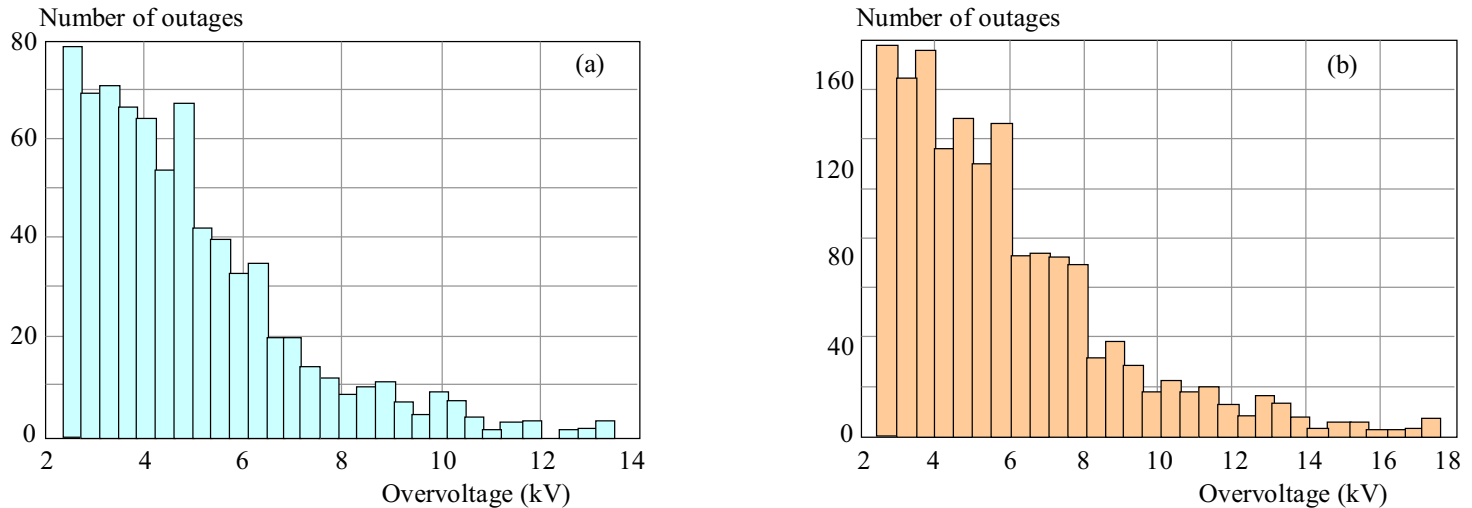

Fig. 8. Distribution of overvoltages causing SFFOR $\left(R_{i}=50 \Omega, \rho=1000 \Omega-\mathrm{m}\right),(\mathrm{a})$ - ATP simulation, (b) - ML method

where $V_{\text {Ins. }}(t)$ is the voltage across the air gap in $\mathrm{kV}$, given by (11), $g$ is the gap length and $l$ is the leader length; $k\left(=7.785 \times 10^{-7}\right)$ is the leader coefficient and $E_{o}(=535 \mathrm{kV} / \mathrm{m})$ is the critical leader inception gradient. When the applied voltage exceeds the corona inception voltage, streamers propagate along the insulator string and if the voltage remains high enough, the streamers will become a leader channel. A breakdown occurs when the leader crosses the gap between the cross arm and the conductor. The striking distance of insulator string is $3.35 \mathrm{~m}$.

To verify the accuracy of the proposed hybrid ML method, the obtained results have been compared to the results of ATP simulation. The line parameters and the number of spans located on each side of the struck tower for both the ML method and ATP simulation were the same.

In order to perform the overvoltage calculation, 40000 values of lightning parameters and tower footing resistance were generated randomly. The convergence of randomly generated parameters was checked by comparing the resultant probability density function of each variable to its theoretical distribution function; the procedure was stopped once the error match within $5 \%$. As an example, Fig. 6 represents the probability distribution function of randomly generated values of the peak current magnitude and the rise time.

In order to evaluate the lightning performance and the overvoltages caused by lightning strokes, firstly, the termination point of impact of each lightning stroke must be determined. Using an EGM model of overhead line, 
Table 4. Lightning flashover rate (LFOR)

\begin{tabular}{cccc}
\hline$R_{i}$ & IEEE Flash & ML Method & ATP \\
\hline $10 \Omega$ & 1.85 & 1.76 & 1.78 \\
$50 \Omega$ & 4.5 & 3.71 & 3.98 \\
$200 \Omega$ & 10.87 & 9.57 & 10.00 \\
\hline
\end{tabular}

the termination point of impact of each lightning stroke has been determined. Assuming a maximum current magnitude of $400 \mathrm{kA}$ [7], the width of the impact area $d$ is $1000 \mathrm{~m}$.

However, depending on SF or BF occurrence, the proper equation to estimate the resultant overvoltage was used. Figs. (7) and (8) present distribution of lightning overvoltages causing SFFOR and BFR on the tower top, respectively.

The distribution of overvoltages, ie maximum value, the mean value and standard deviation of overvoltages caused by SF and BF, estimated by the ML method and ATP simulation, are presented in Tables 2 and 3. The LFOR in Tables 2 and 3 is presented for 40000 simulations.

Owing the results of ATP simulation, the LFOR of overhead line can be predicted with a good accuracy by the ML method. Also, the results show that the computation time of ML method is much less than ATP simulation. This is worth, especially, for large networks with a lot of interested nodes that should be analysed, separately.

Another important stage in the lightning-related studies is to evaluate the insulation risk of failure of power apparatus. This is a component reliability problem, for which a risk formulation had been proposed in the IEC 71-2 insulation coordination standard as [17]

$$
R=\int_{0}^{\infty} f(V) P(V) \mathrm{d} V
$$

where $f(V)$ is the probability density of overvoltage occurrence and $P(V)$ is the probability of disruptive discharge of insulation. The mean value of probability of disruptive discharge of insulation is equal to the value of CFO and the standard deviation is $3 \%$ [18]. Having the risk of failure of (17), the mean time between failure (MTBF) of power apparatus, ie their lifetime can be estimated.

Once the mean value and standard deviation of overvoltages caused by SF and BF has been determined; the resultant distribution function of overvoltages is defined. Then, the failure risk of insulation that is a sum of the risks caused by $\mathrm{SF}$ and $\mathrm{BF}$ is calculated.

Assuming a Gaussian cumulative probability function for disruptive discharge of insulation and overvoltage occurrence $[7,18]$, the failure risk has been calculated by ML method and ATP simulation, for $R_{i}=10 \Omega$ and $R_{i}=50 \Omega$ (Tables 2 and 3 ). Considering the results of ATP simulation, it can be seen that the ML method can predict the insulation risk of failure with a good accuracy and hence is also valid for the risk analysis of power apparatus connected to overhead lines.

It should be mentioned that part away of different values of the mean value and standard deviations estimated in two methods; the ratio of the mean value to the standard deviation of overvoltages (Mean Value/(Std. Dev.)) in both methods is close together. Therefore, the risk area determining insulation failure is almost equal for both methods, see Fig. 9. Then, the insulation failure predicted by ML method is similar to the value estimated by ATP simulation.

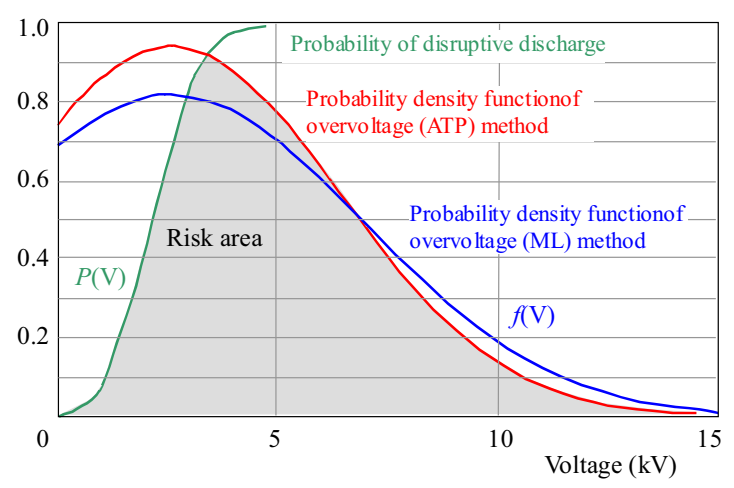

Fig. 9. Insulation risk of failure $\left(R_{\mathrm{i}=50} \Omega\right)$

In order to check the effectiveness of ML method, an additional calculation was performed. In this case, the results of the presented method and those of the IEEE FLASH method [2] has been compared (Table 4). Due to the results, the LFOR estimated by ML method is closer to the results of ATP simulation, than to IEEE Flash program. However, the relative error of the Flash program than with the ATP simulation increases with the tower footing resistance.

Since such a procedure should be performed for each tower footing of different value, its significant effect on the Monte Carlo strategy and the resultant value of overvoltages is evident.

\section{CONCLUSION}

In this paper, a hybrid method for evaluating the lightning performance of overhead lines due to direct strokes is proposed. The presented method is a combination of the travelling wave theory and Monte Carlo approach. Then, it benefits from the simplicity of analytical equations together with the accuracy of the Monte Carlo simulation, simultaneously.

The obtained results by the proposed method show a satisfactory accuracy with far less computation time for calculating lightning overvoltages in comparison with simulation results of a conventional approach such as EMTP/ATP. Therefore, the presented method can be very efficient in terms of time and computational resources for the further analysis like the placement of arrester and/or insulation coordination studies. This is especially important in the case of large power networks 
where a lot of candidate nodes of different characteristic should be analyzed, separately.

The proposed method is also valid for lightning related reliability studies that failure risk of power apparatus must be calculated, in which the lightning overvoltage distribution can be obtained by the presented method with a good accuracy.

Since only a few spans in the vicinity of the struck tower are influenced by the lightning surge, the lightning related studies are considered as a discrete problem. This means that subsystems comprising a few towers and line spans can be modelled, separately, as in the present lightning performance study. However, the proposed method is not going to replace the EMTP/ATP simulation.

\section{Acknowledgment}

The authors gratefully acknowledge the valuable comments by Dr M. Ramezani, Electrical and Computer Engineering Department, University of Birjand, for her precise advices on the Monte Carlo implementation; and the contribution of Dr M. Khorashadizadeh, Applied Mathematics Department, University of Birjand.

\section{REFERENCES}

[1] IEEE Std. 1410. 'IEEE Guide for Improving the Lightning Performance of Electric Power Overhead Distribution Lines', 2010.

[2] IEEE Std. 1243. 'IEEE Guide for Improving the Lightning Performance of Transmission Lines', 1997.

[3] HILEMAN, A. R. : Insulation Coordination for Power Systems, Marcel Dekker, New York, 1999.

[4] ANDERSON, J. G.: Monte Carlo Computer Calculation of Transmission Line Lightning Performance, AIEE Trans. 80 No. 3 (1961), 414-420.

[5] MARTineZ, J. A.-ARANDA, F. C. : Lightning Performance Analysis of Overhead Transmission Lines using the EMTP, IEEE Trans. Power Deliv. 20 No. 3 (2005), 2200-2210.

[6] CURRIE, J. R.-CHOY, L. A.-DARVENIZA, M. : PAS 90 No. 9 (1971), 2305-2312.

[7] SHARIATINASAB, R.-VAHIDI, B.-HOSSEINIAN, S. H. : Statistical Evaluation of Lightning-Related Failures for the Optimal Location of Surge Arresters on the Power Networks, IET Gener. Trans \& Distrib. 3 No. 2 (2009), 129-144.

[8] SHARIATINASAB, R.-VAHIDI, B.-HOSSEINIAN, S. H.AMETANI, A.: Probabilistic Evaluation of Optimal Location of Surge Arresters on EHV and UHV Networks Due to Switching and Lightning Surges, IEEE Trans. Power Deliv. 24 No. 4 (2009), 1903-1911.

[9] SHARIATINASAB, R.-GHAYUR, J. : Probabilistic Evaluation of Lightning Performance of Overhead Distribution Lines Using Monte Carlo Method, Proc. 17th Electric Power Distrib. Network Conf. (EPDC), Tehran, Iran, 2012.

[10] SHAFAEI, A.-GHOLAMI, A.-SHARIATINASAB, R. : Probabilistic Evaluation of Lightning Performance of Overhead
Transmission Lines with Considering Non-Vertical Strokes, Scientia Iranica 19 No. 3 (2012), 812-819.

11] RIZK, F. A. M. : Modeling of Transmission Line Exposure to Direct Lightning Strokes, IEEE Trans. Power Deliv. 5 No. 4 (1990), 1983-1997.

12] CIGRE Working Group 01 (Lightning) of Study Committee 33 (Overvoltages and Insulation Coordination). "Guide to Procedures for Estimating the Lightning Performance of Transmission Lines," CIGRE Brochure 63, Paris, Oct. 1991.

[13] MOUSA, A. M. : The Soil Ionization Gradient Associated with Discharge of High Currents into Concentrated Electrodes, IEEE Trans. Power Deliv. 9 No. 3 (1994), 1669-1677.

14] IEEE TF on Parameters of Lightning Strokes. Parameters of Lightning Strokes: a Review, IEEE Trans. Power Deliv. 20 No. 1 (2005), 346-358.

[15] De ALMEIDA, A. B.-ENGELBERCHT, C. S.-PESTANA, R.-BARBOSA, F. P. M.: Prediction of Faults Caused by Lightning for Transmission System Operations, ELECTRA No. 254 (Feb 2011).

16] HEIDLER, F.-CVETIC, J. M.-STANIC, B. V. : Calculation of Lightning Current Parameters, IEEE Trans. Power Deliv. 14 No. 2 (1999), 399-404.

[17] IEC Std. 71-2. 'Insulation Coordination: Application Guide', 1996.

[18] ORILlE-FERNNDEZ, A. L.-BOGARRA, S.-GOTÉS, M. A.: Optimization of Surge Arrester's Location, IEEE Trans. Power Deliv. 19 No. 1 (2004), 145-150.

Received 12 July 2014

Reza Shariatinasab was born in Iran on September 1, 1977. He received the $\mathrm{PhD}$ degree in Electrical Engineering from Amirkabir University of Technology, Tehran, Iran, in 2009. Currently, he is an Assistant Professor of Electrical Engineering in Electrical and Computer Engineeriung Department, University of Birjand, Birjand, Iran. His research interests include power system transients, lightning and switching protection, electrical insulation and high voltage technology.

Pooya Tadayon was born in Iran on September 29, 1988. He received the MSc Degree in Electrical Engineering from University of Birjand, Birjand, Iran, in 2012. Currently, he is a Lecturer at Islamic Azad University, Iran. His research interests include DG, power quality and power system transients.

Akihiro Ametani received the $\mathrm{PhD}$ degree in power system transients from the University of Manchester Institute of Science and Technology (UMIST), Manchester, UK, in 1973. He was with the UMIST from 1971 to 1974, and Bonneville Power Administration, Portland, OR, and developed an Electromagnetic Transients Program for Summers 1976 to 1981. He has been a Professor with Doshisha University, Kyoto, Japan, since 1985 and was a professor at the Catholic University of Leaven, Leuven, Belgium, in 1988. He was a VicePresident of The Institute of Electrical Engineers of Japan in 2003 and 2004. Dr Ametani is a Chartered Engineer in the UK, a Fellow of IET, a Fellow of IEEE and a Distinguished member of CIGRE. He received the DSc degree (higher degree in UK) from the University of Manchester in 2010. 